\title{
Ultrasound assisted enhanced extraction of lutein $(\beta, \varepsilon$-carotene- 3, 3'-diol) from Mircroalga (Chlorella pyrenoidosa) grown in wastewater: Optimization through Response Surface Methodology
}

\author{
Arun J. ${ }^{1}$ Avinash U. ${ }^{1}$, Arun Krishna B. ${ }^{1}$, Pandimadevi M. ${ }^{2}$ and Gopinath K.P. ${ }^{1, *}$ \\ ${ }^{1}$ Department of Chemical Engineering, SSN College of Engineering, Rajiv Gandhi Salai (OMR), Kalavakkam - 603110, Tamil Nadu, India. \\ 2Department of Biotechnology, School of Biosciences, SRM University, Kattankulathur - 603203, Tamil Nadu, India. \\ Received: 12/07/2017, Accepted: 12/10/2017, Available online: 30/10/2017 \\ *to whom all correspondence should be addressed: e-mail: gopinathkp@ssn.edu.in
}

\section{Abstract}

One of the fundamental carotenoid compounds available in microalga Chlorella pyrenoidosa is lutein, which is a commercially valuable antioxidant compound. The extraction of lutein from $C$. pyrenoidosa was studied in detail under various operating conditions. Acid pretreatment was done using $10 \% \mathrm{HCl}$. To analyze the effectiveness of ultrasound based extraction, experiments were carried out in presence and absence of ultrasonication. The results showed increased lutein yields in presence of ultrasonication. Scanning electron micrographs of pretreated and ultrasonicated algae cells showed increased surface area due to formation of porous surface. There were no significant contrasts in antioxidant activity of lutein between the samples obtained from ultrasound and acid treatment. Furthermore, to optimize the operating parameters like concentration of $\mathrm{HCl}$, ultrasound exposure time and microalga biomass concentration, response surface methodology (RSM) design was applied. From the experimental results the optimum values derived are incubation time $41.34 \mathrm{~min}, \mathrm{HCl}$ concentration $15.63 \%$ and biomass concentration 309.21 $\mathrm{g} / \mathrm{L}$ for a yield of $3.5 \mathrm{mg}$ of lutein per gram of algae. Hence, ultrasound extraction with acid treatment is the most efficient technique for the extraction of microalgal lutein.

Keywords: C. pyrenoidosa; lutein; optimization; ultrasound; anti-oxidant

\section{Introduction}

Microalgae are photosynthetic organisms that grip nitrogen $(N)$ and phosphorus $(P)$ in the midst of their improvement and ends up in biomass yield. This generated biomass can be changed over into a significant product through appropriate methodology (Ometto et al., 2014). All the above, the freshwater microalgae bends towards the $\mathrm{N}$ and $\mathrm{P}$ concentrations level in their biomass in association with environment in the wastewater (Beuckels et al. 2015; Choi et al., 2015). Microalgae are the established commercial sources of high-regard chemicals, for instance, $\beta$-carotene, astaxanthin, docosahexaenoic acid, phycobilin pigments and algal concentrates for use in beauty care products. Microalgae are in like manner continuously having an impact in cosmaceuticals, nutraceuticals and food supplements. Over the latest couple of years, there has been energized excitement for microalgae as commercial sources of these and other highvalued products, driven mostly by the endeavors to grow industrially feasible biofuels from microalgae (Borowitzka, 2013).

Municipal solid waste (MSW) management is the major environmental concern and challenging process worldwide (Bogiatzidis and Komilis, 2016). In recent years, with increased global concern over energy demand and greenhouse gas accumulation, global countries have turned their efforts towards renewable energy from wastewater. Studies on anaerobic process, with high loading rate, methane gas production and less nutrients, were reported (Diamantis and Aivasidis, 2010; Blika et al., 2009; Vlassis, 2012).

Lutein, one of the essential xanthophyll components assuming an imperative part in preventing or enhancing the impacts of various degenerative human diseases, for example, chronic diseases, age related macular degeneration. Due its far reaching utilize the worldwide lutein market has developed essentially in the current years with US offers of over $\$ 150$ million every year (Fernandez et al., 2015). Ultrasound extraction has been applied to extract the components from plant and animal materials, for example, oil, protein, polyphenolics, and pigments. The yield of carotenoids extracted from Dunaliella salina by ultrasound was higher than that by supercritical liquid extraction (Macías et al., 2008). The yield of lutein from $C$. vulgaris by ultrasound was the highest when compared with and maceration, soxhlet extraction, and pressurized fluid extraction (Cha et al., 2010). 
In this study, ultrasound assisted lutein extraction with/without acid pretreatment conditions from the microalga $C$. pyrenoidosa were optimized by response surface methodology (RSM). Moreover, the effect of ultrasound with/without acid pretreatment on the morphology of the microalgal cell, and the antioxidant activities of lutein were also determined.

\section{Materials and methods}

\subsection{Wastewater}

The wastewater utilized for the study was obtained from the wastewater treatment plant at Sri Sivasubramaniya
Nadar College of Engineering, Chennai, Tamilnadu. Before the experiments, pretreatment of wastewater is done by removing large solid particles by using filter cloth (Kimberly-Clark) and autoclaved at $121^{\circ} \mathrm{C}$ for $15 \mathrm{~min}$. After that chilled down to room temperature, and then kept undisturbed for settling of dissolved solids at $4{ }^{\circ} \mathrm{C}$, After couple of days the supernatant is taken up for the further analyses. This wastewater is utilized for the development of microalgae; the nitrogen $(N)$, phosphorus $(P)$, and chemical oxygen demand (COD) were resolved utilizing the protocol specified for each test (Hach, 2008). The initial characteristics of the wastewater are seen in Table 1.

Table 1. RSM design for ultrasonic extraction.

\begin{tabular}{cccccc}
\hline $\begin{array}{c}\text { Run } \\
\text { order }\end{array}$ & $\begin{array}{c}\text { Exposure } \\
\text { Time (Min) }\end{array}$ & $\begin{array}{c}\text { HCL Concentration } \\
(\%)\end{array}$ & $\begin{array}{c}\text { Biomass } \\
\text { Concentration (g/L) }\end{array}$ & $\begin{array}{c}\text { Lutein Yield (mg/g) } \\
\text { Experimental value }\end{array}$ & $\begin{array}{c}\text { Lutein Yield (mg/g) } \\
\text { Predicted value }\end{array}$ \\
\hline 1 & 30 & 10 & 200 & 2.73 & 2.62416 \\
\hline 2 & 15 & 15 & 100 & 2.08 & 2.11091 \\
\hline 3 & 45 & 5 & 100 & 1.77 & 1.68952 \\
\hline 4 & 15 & 5 & 100 & 2.04 & 1.98411 \\
\hline 5 & 30 & 10 & 200 & 2.83 & 2.62416 \\
\hline 6 & 30 & 10 & 31.821 & 1.71 & 1.77085 \\
\hline 7 & 45 & 15 & 300 & 3.41 & 3.44517 \\
\hline 8 & 45 & 5 & 300 & 2.83 & 2.77837 \\
\hline 9 & 4.7731 & 10 & 200 & 2.04 & 2.01351 \\
\hline 10 & 15 & 5 & 300 & 1.97 & 2.14296 \\
\hline 11 & 30 & 200 & 3.23 & 2.07598 \\
\hline 12 & 30 & 1.591 & 368.179 & 2.82 & 3.19845 \\
\hline 13 & 30 & 10 & 200 & 2.52 & 2.74332 \\
\hline 14 & 30 & 18.409 & 200 & 2.48 & 2.62416 \\
\hline 15 & 30 & 10 & 200 & 1.92 & 2.62416 \\
\hline 16 & 45 & 10 & 100 & 2.32 & 1.90632 \\
\hline 17 & 55.2269 & 15 & 200 & 2.66 & 2.37579 \\
\hline 18 & 15 & 10 & 300 & 2.56 & 2.71976 \\
\hline 19 & 30 & 15 & 200 & 2.63 & 2.62416 \\
\hline 20 & 30 & 10 & 200 & & 2.62416 \\
\hline
\end{tabular}

\subsection{Microalgae cultivation}

C. pyrenoidosa was cultivated mixotrophically utilizing blend of wastewater and $f / 2$ medium [9]. The algae culture was at that point acclimatized to develop in wastewater. For better development, the blend contains around $80 \%$ (by volume) of wastewater and $20 \%$ of $f / 2$ medium. The microalgae was developed in a photo bioreactor (Fig.1) of 60 L capacity, agitated bubbling air ( $5 \%$ carbon dioxide) under 5000 lux illuminated white fluorescent bulb for 12:12 $\mathrm{h}$ light and dark condition for 15 days. The biomass was monitored and harvested via auto-flocculation and filtering process. Then the micro algal paste was rinsed with distilled water to remove residual salts and oven dried.

\subsection{Initial trials for lutein extraction}

Initial trials with various ranges of Biomass concentration, $\mathrm{HCl} \%$ and Incubation time were performed for lutein extraction. Pre-RSM extraction trials for incubation time, biomass concentration, and percentage $\mathrm{HCl}$ were carried out in the following ranges: $15 \mathrm{~min}-45 \mathrm{~min}$ (increments of $15 \mathrm{~min}$ ), Biomass concentration 0.5-3.0g (increments of
$0.5)$, and $5-15 \% \mathrm{HCl}$ (increments of $5 \%$ ). Accordingly, then, these ranges were utilized as the upper and lower limits for the RSM design of experiment.

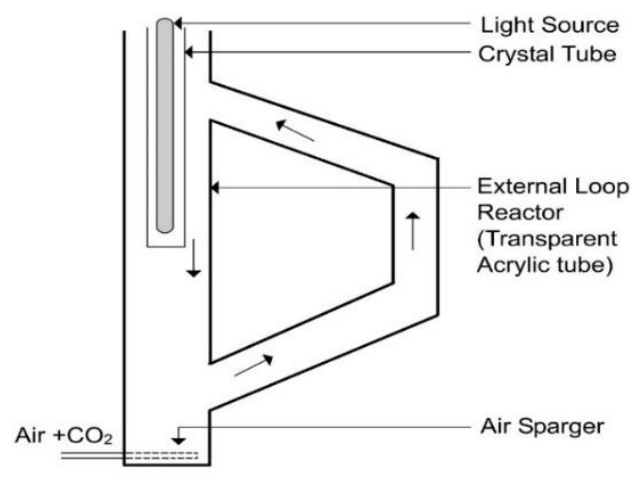

Figure 1. Photo bioreactor

\subsection{Extraction}

\subsubsection{Ultrasound extraction}


Ultrasound extraction was performed in an ultrasonic generator (VCX750, Sonic and Materials Inc, Newtown, USA) with settled recurrence of $35 \mathrm{kHz}$ and constrain of $55 \mathrm{~W} / \mathrm{cm}^{2}$. Two grams of C. pyrenoidosa with $90 \%$ ethanol was taken in a conical flask, and afterward the jar was held in the ultrasonic tank for extraction at different incubation times and $\mathrm{HCL} \%$. Optimization of the ultrasound extraction condition was refined by using the response surface method (RSM) with a central composite design (CCD) (Deenu et al. 2013). Three distinct variables (Incubation time, $\mathrm{HCL} \%$ and biomass concentration) were used at three equidistant levels $(-1,0$, and +1$)$ (Table 1$)$. The concentrate was filtered through Whatmann No. 1 paper lastly stored at 4으 for further examination.

\subsubsection{Acid pretreatment}

Acid pretreatment of $C$. pyrenoidosa was performed by incubating two grams of microalgae in a $100 \mathrm{~mL}$ of $10 \%$ $\mathrm{HCL}$, and after that incubated at $50{ }^{\circ} \mathrm{C}$ or overnight. The improvement of the acid pretreatment condition was controlled by response surface system (RSM) with a central composite design (CCD).

\subsubsection{Ultrasound extraction after acid pretreatment}

Fresh C. pyrenoidosa (two grams) was incubated with $10 \%$ $\mathrm{HCL}$ for 30mins and afterward sonicated at fixed frequency and intensity $\left(35 \mathrm{kHz}, 55 \mathrm{~W} / \mathrm{cm}^{2}\right)$. The ultrasound extraction after acid pretreatment was optimized by reaction surface methodology (RSM), with a central composite design (CCD). The concentrate was filtered through Whatmann No. 1 paper and after that kept at $4{ }^{\circ} \mathrm{C}$ without light for further examination.

\subsection{Purification of lutein}

The $C$. pyrenoidosa concentrate was saponified by including $6 \% \mathrm{KOH}(\mathrm{w} / \mathrm{v})$ at $50{ }^{\circ} \mathrm{C}$ for $30 \mathrm{~min}$. The blend was then subjected to rotational evaporator and the dry solid acquired was dissolved in refined water $(200 \mathrm{~mL})$ and 200 $\mathrm{mL}$ ethyl acetate is added to it. At that point subjected to rotating evaporator and re-dissolved in $5 \mathrm{~mL}$ of acetone. The acetone solution $(2 \mathrm{~mL})$ was stacked on a silica gel fragment $(2.0 \times 60.0 \mathrm{~cm})$, and after that eluted with $150 \mathrm{~mL}$ of hexane, followed by $300 \mathrm{~mL}$ of hexane-acetone $(7: 3 \mathrm{v} / \mathrm{v})$. Further the separated portion is dried and stored at $20^{\circ} \mathrm{C}$.

\subsection{HPLC analysis of Lutein}

The filtrate of $20 \mu \mathrm{L}$ was infused into the HPLC system ( Perkin Elmer, USA) Separation was performed using a C18 column $(5 \mathrm{~mm}, 150 \mathrm{~mm} \times 46)$ at $30^{\circ} \mathrm{C}$. The mobile phase comprised of methanol/acetonitrile (90:10 V/V). The aggregates were eluted at a stream rate of $1 \mathrm{ml} / \mathrm{min}$ and the lutein content was detected utilizing an UV visible spectrophotometer (Model V630, JASCO Analytical Instruments, Japan) by measuring absorbance at the wavelength range of $300-600 \mathrm{~nm}$. The maximal absorbance (445 nm) was taken up for evaluation of lutein concentrates.

\subsection{Microalgal cell morphology}

Microalgal cell morphology was considered on the dried cell procured by each extraction procedure (ultrasound extraction, acid treatment and ultrasound extraction with acid pretreatment). The surface characteristics were recorded using Scanning Electron Microscope (Hitachi S3400 Model, Tokyo, Japan) at the extent of $30 \sim 200 \mathrm{kV}$ voltage.

\subsection{Experimental design and optimization by central composite design (CCD)}

Perfect condition for the lutein extraction from the microalgae was analyzed by response surface methodology (RSM) and the imperative class of second- order design called central composite design (CCD) was used for the examination. Advance studies were carried out by considering the effect of three variables likely $\mathrm{HCl} \%$, incubation time and biomass concentrations. To depict the effect of these three components, a full factorial CCD inciting 20 sets of tests were performed. The test outline and results of the CCD were appeared in Table 1 . The conduct of the system is clarified by the next second-order polynomial model:

$$
Y=b_{o}+\sum_{i=1}^{3} B i X i+\sum_{i=1}^{3} B i i i^{2}+\sum_{i=1}^{3} \sum_{j=i+1}^{3} B i j X i j
$$

Variance analysis was conducted and the binary quadratic condition (Eq. 1) was developed where $Y$ is the anticipated response, $b_{0}$ is the intercept, $B_{i}$ is the linear coefficient, $B_{i j}$ are the quadratic coefficients, and $X_{i}$ and $X_{j}$ are the levels of the independent variables. Experimental data generated from the central composite design were fitted to a secondorder polynomial regression model were fitted to a secondorder polynomial predicted regression model (Eq. 2) where $Y$ is the anticipated response (here, lutein yield), and $X_{1}$ (incubation time), $\mathrm{X}_{2}(\mathrm{HCl} \%)$ and $\mathrm{X}_{3}$ (biomass concentration) are the coded estimations of the independent variables.

$$
Y=b_{0}+\left(b_{1} x_{1}\right)+\left(b_{2} x_{2}\right)+\left(b_{3} x_{3}\right)+\left(b_{11} x_{1}{ }^{2}\right)+\left(b_{22} x_{2}{ }^{2}\right)+\left(b_{33} x_{3}{ }^{2}\right)+\left(b_{12} x_{1} x_{2}\right)+\left(b_{23} x_{2} x_{3}\right)+\left(b_{31} x_{3} x_{1}\right)
$$

A statistical program was utilized for regression examination of the data got and to gauge the coefficients of the regression equations. Examination of difference (ANOVA) was used for graphical examination of the data in order to acquire data of process elements with the response. The nature of fit of polynomial model conditions was communicated by the coefficient of determination $\mathrm{R}^{2}$.

\subsection{Determination of antioxidant activities}

\subsubsection{DPPH radical scavenging assay}


The DPPH examine was resolved by the technique for Duan et al. (2006). $0.5 \mathrm{~mL}$ of the sample at various concentrations was blended with $0.5 \mathrm{~mL}$ of $0.16 \mathrm{mM} \mathrm{DPPH}$ in methanol and afterward incubated at $37^{\circ} \mathrm{C}$ for $30 \mathrm{~min}$ in dark. The absorbance was measured at $517 \mathrm{~nm}$. The rate of DPPH radical scavenging activity was calculated using the following equation:

$$
\text { Scavenging activity }(\%)=\left(1-\frac{O D_{\text {Treated }}}{O D_{\text {Control }}}\right) \times 100
$$

\subsubsection{Reducing power}

The reducing power was measured by the technique for Chou et al., (2009). The sample at various concentrations $(100-500 \mu \mathrm{g} / \mathrm{mL})$ in ethanol $(0.25 \mathrm{~mL})$ was added to $0.25 \mathrm{~mL}$ of sodium phosphate buffer ( $0.2 \mathrm{M}, \mathrm{pH} 6.6)$ and $0.25 \mathrm{~mL}$ of $1 \%$ potassium ferricyanide. At that point, the blend was brooded at $50{ }^{\circ} \mathrm{C}$ for $20 \mathrm{~min}$. The $0.25 \mathrm{~mL}$ of $10 \%$ trichloroacetic acid was added to the blend to stop the reaction, and afterward the blend was centrifuged at $12,000 \mathrm{~g}$ for $10 \mathrm{~min}$. The supernatant $(0.4 \mathrm{~mL})$ was mixed with $0.4 \mathrm{~mL}$ of ethanol and $80 \mu \mathrm{L}$ of $0.1 \%$ ferric chloride solution and kept undisturbed for $10 \mathrm{~min}$, and the absorbance was measured at $700 \mathrm{~nm}$.

\subsubsection{ABTS radical scavenging activity}

ABTS radical scavenging activity of lutein was resolved by the technique for Re et al., (1999) with a few changes. The radical $\mathrm{ABTS}^{\circ+}$ was produced by reacting $7 \mathrm{mM}$ ABTS and $2.45 \mathrm{mM}$ potassium persulfate buffer (1:1) and kept for 16 $\mathrm{h}$ in dark at room temperature. After $16 \mathrm{~h}$, ethanol was utilized to adjust the absorbance of the radical $A B T S^{\circ+}$ to $0.75 \pm 0.07$ at $734 \mathrm{~nm} .1 .9 \mathrm{~mL}$ of the radical $\mathrm{ABTS}^{\bullet+}$ was added to $100 \mu \mathrm{L}$ of the sample at different concentrations. Butylated hydroxytoluene (BHT) is used as standard. The blend was remained at room temperature for $6 \mathrm{~min}$, and afterward the absorbance was measured at $734 \mathrm{~nm}$. Scavenging activity was calculated using the above equation (3).

\subsubsection{Hydrogen peroxide radical scavenging activity}

Hydrogen peroxide radical scavenging activity was resolved by the technique for Muller (2001). The reaction mixture comprised of $20 \mu \mathrm{L}$ of $2 \mathrm{mM} \mathrm{H}_{2} \mathrm{O}_{2}, 100 \mu \mathrm{L}$ of $0.1 \mathrm{M}$ phosphate buffer ( $\mathrm{pH} 5.0)$, and $100 \mu \mathrm{L}$ of sample, and after that incubated at $37{ }^{\circ} \mathrm{C}$ for $5 \mathrm{~min}$. At that point, $30 \mu \mathrm{L}$ of $1.25 \mathrm{mM} \mathrm{ABTS}$ and $30 \mu \mathrm{L}$ peroxidase (1 unit/mL) were added to the reaction mixture and incubated at $37^{\circ} \mathrm{C}$ for $10 \mathrm{~min}$. The absorbance was measured at $405 \mathrm{~nm}$. The rate of hydrogen peroxide radical rummaging movement was calculated using the above equation (3).

\section{Results and Discussion}

\subsection{Characteristics of wastewater after biomass recovery}

Microalgae play an important role in biological processes coupled with bioremediation of wastewaters due to its competence to assimilate organic compounds and nutrients. Fig. 2. elaborates the characteristics of wastewater after biomass recovery. Wastewater with elevated concentrations of Phosphorus, Nitrogen, COD and TSS when discharged into the water bodies, leads to contamination of water bodies. To prevent this dilemma, our results show that microalgae treatment is economically viable process for treating the waste water effluents prior to dumping into the water bodies. The concentrations of Phosphorus, Nitrogen, COD, and TSS are reduced by about $97.93 \%, 97.7 \%, 91.08 \%$ and $88.73 \%$ respectively.

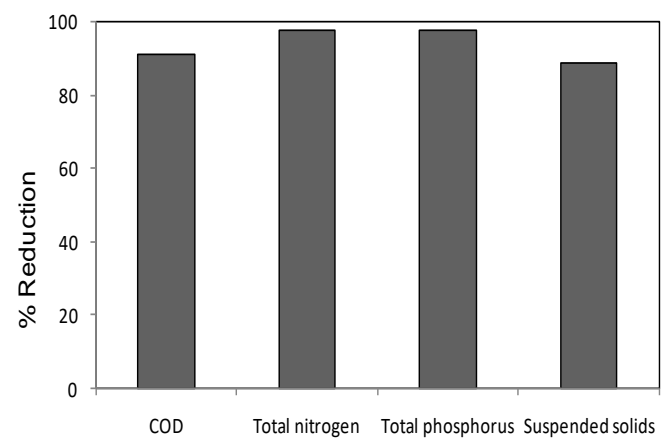

Figure 2. Characteristics of wastewater after biomass recovery

\subsection{Initial trials for RSM optimization}

Pre-RSM extraction trials for the variables incubation time, biomass concentration, and $\mathrm{HCl} \%$ were studied in the following ranges: $15 \mathrm{~min}-45 \mathrm{~min}$ (increments of $15 \mathrm{~min}$ ), Biomass concentration 0.5- 3.0g (increments of 0.5), and $5-15 \% \mathrm{HCl}$ (increments of $5 \%$ ). The effect of $\mathrm{HCl}$ concentration on lutein yield was studied and results were elaborated on Fig.3A. The effect of incubation time (15$45 \mathrm{mins}$ ) on lutein yield was studied and results were elaborated on Fig. 3B. At fixed $10 \% \mathrm{HCl}$ concentration with 30 mins incubation time resulted in a higher lutein yield. Accordingly then, the ranges were fixed for the upper and lower limits for the RSM design of experiment. The better fit between the varying incubation time (15-45min) and $\mathrm{HCl}$ concentration (5-15\%) was studied and furnished in Fig.3C. Here, the 30min incubation time and $10 \% \mathrm{HCl}$ concentration emerged as better conditions for the study. Fig 3D, elaborates the different conditions $(\mathrm{HCl}$, Ultrasound, Ultrasound $+\mathrm{HCl}$ ) adopted and their effectiveness for the lutein yield. Ultrasound with $\mathrm{HCl}$ extraction procedure showed a higher lutein yield than other two methods.

\subsection{Spectral characterization of carotenoid lutein}

Usually, to obtain pure carotenoid compounds practically a few phases of purification process are required. The spectrophotometric components of carotenoids are used to recognize and quantify the individual carotenoid lutein that has been purified. The spectrophotometric examination of the crude extract was analyzed from 300 to $600 \mathrm{~nm}$. Because of extensive conjugated polyene chain, carotenoids show yellow, orange, and red colors (Landrum, 2010). They have retention maxima in the range of $420-480$ $\mathrm{nm}$. Thusly, carotenoids can show a unique molecular 
shape, compound reactivity, and light fascinating properties.
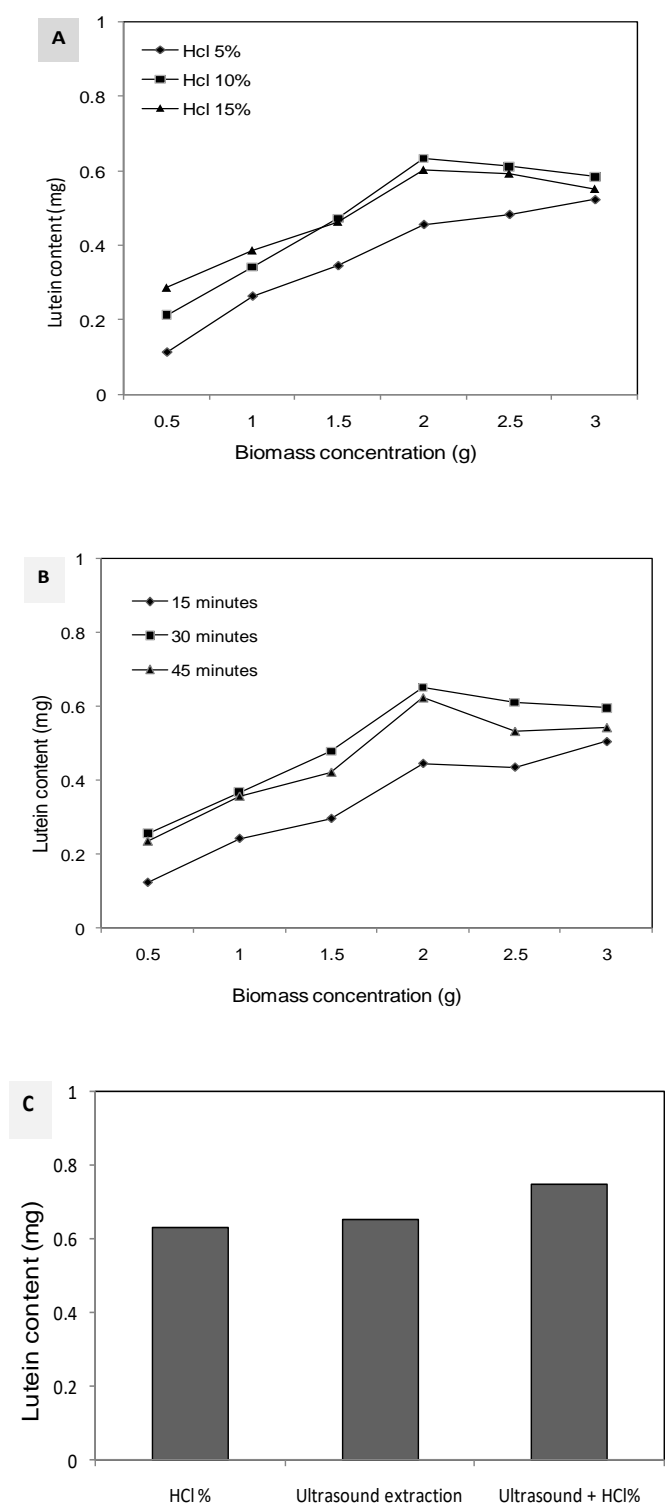

Figure 3. Initial trials for Lutein yield 3A) Effect of $\mathrm{HCl} \%$, 3B) Effect of ultrasound duration, 3C) Maximum lutein yield from different methods

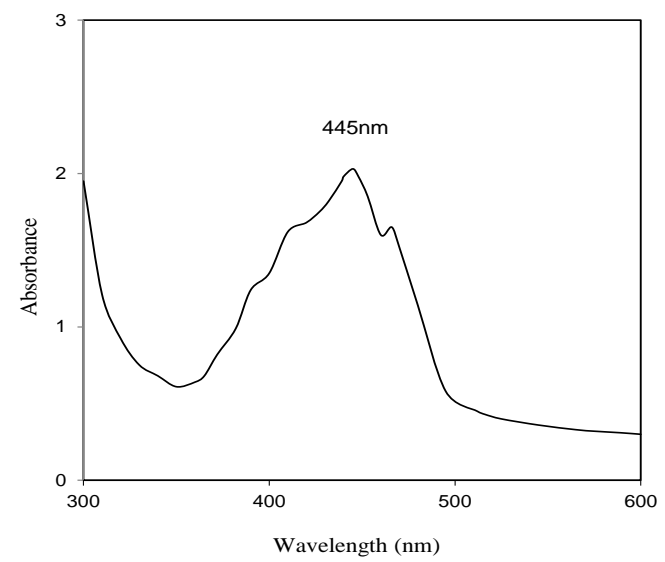

Figure 4. UV-visible spectrum of the extracted Lutein

\subsection{HPLC analysis}

The carotenoid profile was assessed by HPLC after a reference extraction procedure. As was found, absorbance disclosure at $445 \mathrm{~nm}$ allows the confirmation of the carotenoids down to the chromatogram stretches out with awesome linearity (Huck et al., 2000).

Partition of lutein was performed on C18 turn column and an UV photodiode cluster pointer. Figure $5(A)$ standard peak (10 $\mu \mathrm{g} \mathrm{mL-1);} \mathrm{Fig.} 5$ (B) plots the separation of lutein in the chromatogram at $4.52 \mathrm{~min}$ from $C$. pyrenoidosa.
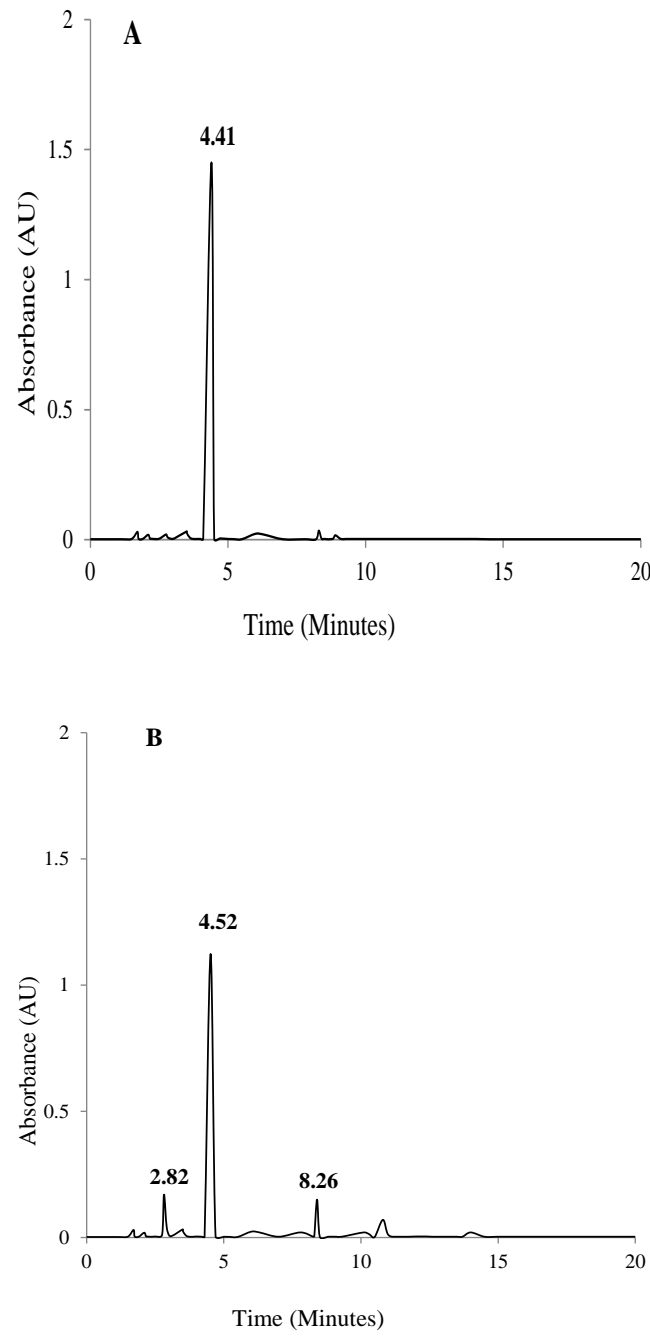

Figure 5. HPLC Chromatogram of the microalgal Lutein at $445 \mathrm{~nm}$. 5A) Standard peak; 5B) microalgal lutein compound.

\subsection{Micro algal cell morphology}

The microalgal cell morphology was determined by scanning electron microscope. The pictures of $C$. pyrenoidosa treated by ultrasound with/without acid pretreatment are shown in Fig. 6. The microstructure of the microalgal cell by ultrasound (Fig. 6C) had more interspaces and openings than the microalgal cell by the acid treatment system (Fig. 6B). The disturbance in the microalgal cell walls by ultrasound extraction is showed up in Fig. 6C. This was the same as the results of (Zhao et al., 2012; Li et al., 2012) 
in which ultrasound treated damaged tissues and cell walls. In addition, the physical unsettling influence of $C$. pyrenoidosa cells by ultrasound, together with acid pretreatment, was the most effective technique to destroy microalgal cell wall (Fig. 6D).

The cell walls were harmed by the usage of ultrasound and acid pretreatment, which brought about the more prominent penetration of solvent into the sample matrix, extended the contact surface region between the solid and liquid phase, and in this manner, the solute immediately diffused from the solid phase to the solvent. Henceforth, ultrasound treatment is significantly more gainful and quick for the extraction of the bioactive compound. Therefore, sonication is expected as a crucial part in separating the microalgal cell walls to upgrade the extraction yield (Chua et al., 2009).

\subsection{Optimization studies}

\subsubsection{Experimental design analysis}

The batch runs were conducted with experiments designed through CCD to visualize the effects of independent factors on responses and the results were evaluated. Approximating function obtained for lutein yield is given as

$$
\begin{aligned}
& Y=1.525+0.0137 X_{1}+0.0463 X_{2}-6.827 \times 10^{-4} X_{3} \\
& -6.749 \times 10^{-4} X_{1}{ }^{2}-0.00303 X_{2}{ }^{2}-4.932 \times 10^{-6} X_{3}{ }^{2} \\
& +0.0003 X_{1} X_{2}+0.000155 X_{1} X_{3}+0.000225 X_{2} X_{3}
\end{aligned}
$$

ANOVA results of these quadratic models are presented in Table 2, indicating that these quadratic models can be used to navigate the design space.

Table 2. ANOVA table for design analysis.

\begin{tabular}{ccccccc}
\hline Source & Degree of freedom & Adj SS & Seq SS & Adj MS & F & P \\
\hline Regression & 9 & 4.09205 & 4.09205 & 0.45467 & 34.12 & 0 \\
\hline Linear & 3 & 3.1561 & 3.1561 & 1.05203 & 78.95 & 0 \\
\hline Square & 3 & 0.3982 & 0.3982 & 0.13273 & 9.96 & 0 \\
\hline Interaction & 3 & 0.53775 & 0.53775 & 0.17925 & 13.45 & 0.001 \\
\hline Residual error & 10 & 0.13325 & 0.13325 & 0.01332 & & \\
\hline Lack of fit & 5 & 0.0439 & 0.0439 & 0.00878 & 0.49 & 0.773 \\
\hline Pure error & 5 & 0.08935 & 0.08935 & 0.01787 & & \\
\hline Total & 19 & 4.2253 & & & &
\end{tabular}

\subsubsection{Main effect plot}

The effect of elements on the reaction (lutein yield) could be examined from the effect plots. The main effect plot for the incubation time, biomass concentration, and $\mathrm{HCl} \%$ is appeared in Fig. 2. The individual centrality of these components can be foreseen from this plot. In traditional optimization, one variable is changed at time keeping remaining parameters as steady. While RSM takes a gander at the simultaneous effect of all the included components and thus, the main effect plot obtained in this study depicts not only the effect of progress of one variable furthermore a merged effect of progress in the elements, which is just imparted by considering one calculate record. The plot proposes that the change in incubation concentration and $\mathrm{HCl} \%$ impacts the lutein yield.

\subsubsection{Reaction surface plots}

The response surface contour plots are shown in Fig. 3. From these plots, it can be deciphered that the \%lutein yield is higher at $10 \%$ of $\mathrm{HCl}$ concentration and incubation time of $30 \mathrm{mins}$. The yields of the lutein were $3.78 \mathrm{mg} / \mathrm{g}$ (Cha et al., 2010) and $9.22 \mathrm{mg} / \mathrm{g}$ dry weight of $C$. vulgaris by ultrasound extraction, in which the dried $C$. vulgaris was used as an unrefined (crude) material. Freeze drying or lyophilization has been extensively used for drying microalgae in research labs; regardless, freeze drying is unreasonably expensive for use in a tremendous scale business recovery of microalgal products (Sevilla et al. 2010).

\subsubsection{Global solution}

Global solution for predicted reactions for the factors, for example, $\mathrm{HCl}$ concentration, incubation time and biomass concentration are fitted and cross checked with the diverse examinations of CCD plan with the parameters Incubation time $=41.34 \mathrm{~min}, \mathrm{HCl}$ concentration $=15.63 \%$ and Biomass concentration $=309.21 \mathrm{~g} / \mathrm{L}$ which brings about a $3.5 \mathrm{mg}$ of lutein yield per gram of microalgae through the extraction technique.

\subsection{Antioxidant activity}

It is outstanding that the assessment of the antioxidant capacities on a chosen antioxidant requires more test frameworks (Yu et al., 2002). The DPPH free radical is a steady free radical that has been generally utilized as an instrument for evaluating the free radical- scavenging activity of antioxidant (Nagai et al., 2003). The ABTS is broadly utilized in food analysis since it is not subject to $\mathrm{pH}$ varieties and is useful to analyze both hydrophilic and lipophilic mixes (Zanfini et al., 2009). Hydrogen peroxide itself is not extremely responsive, but rather it can once in a while be harmful to a cell, since it can bring the hydroxyl radicals to greater extent. In this manner the removal of $\mathrm{H}_{2} \mathrm{O}_{2}$ is important for antioxidant defense in cell or food systems (Subhashini et al., 2011). The reducing capacity of a compound may fill in as a critical marker of its potential antioxidant activity (Duh, 1998). DPPH radical scavenging movement of microalgae is exhibited in Fig.7A. The lutein haunted the capacity to scavenge DPPH at different degrees; with the $250 \mu \mathrm{g}$ concentration of $C$. pyrenoidosa $(81.25 \%)$ was bring into being the most potent scavenger 
Ferric reducing action of microalgae lutein is exhibited in Fig 7B.
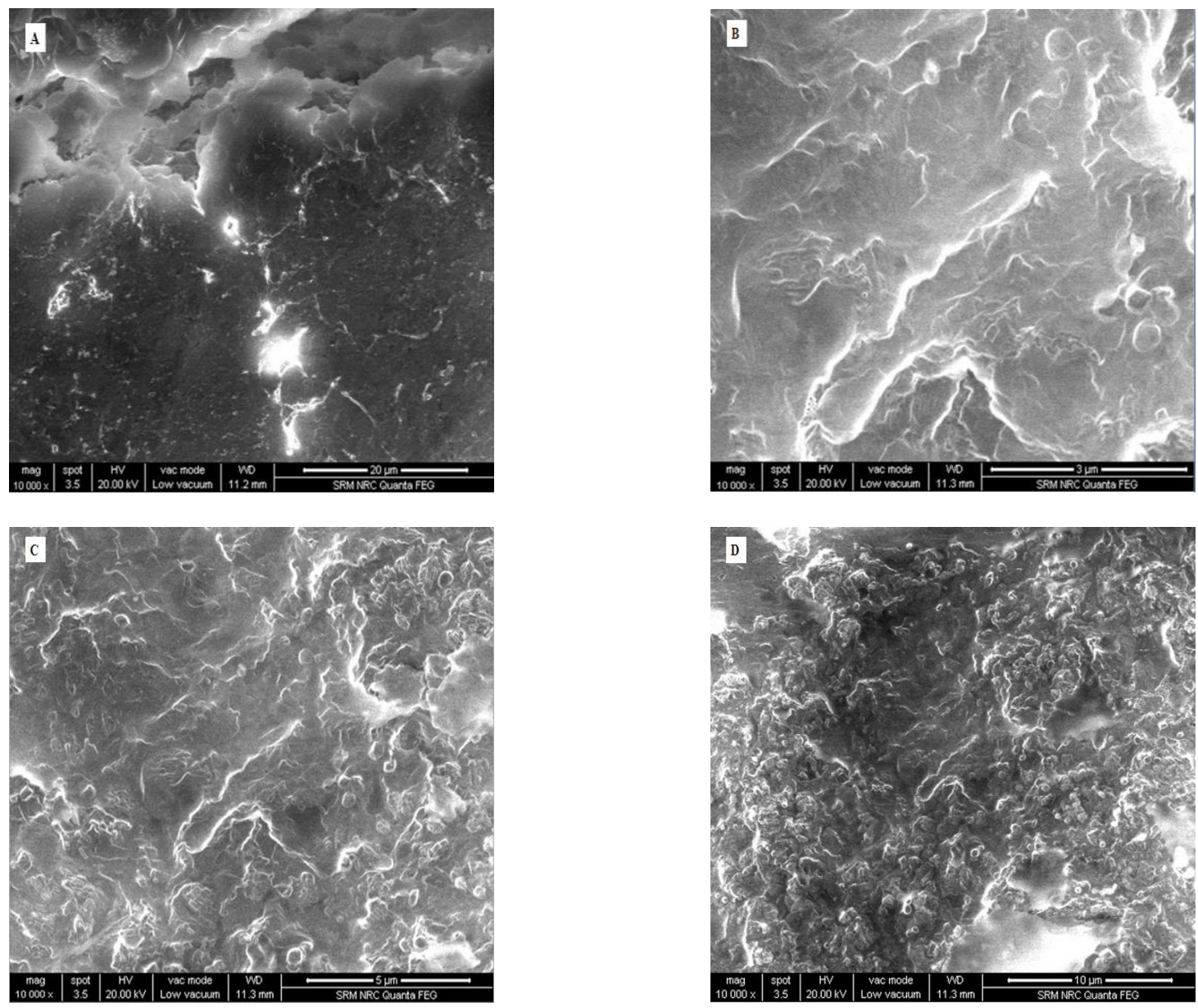

Figure 6. Scanning electron microscope images of $C$. pyrenoidosa. (A) Control; (B) Acid extraction; (C) ultrasound extraction; and (D) ultrasound extraction with acid pretreatment

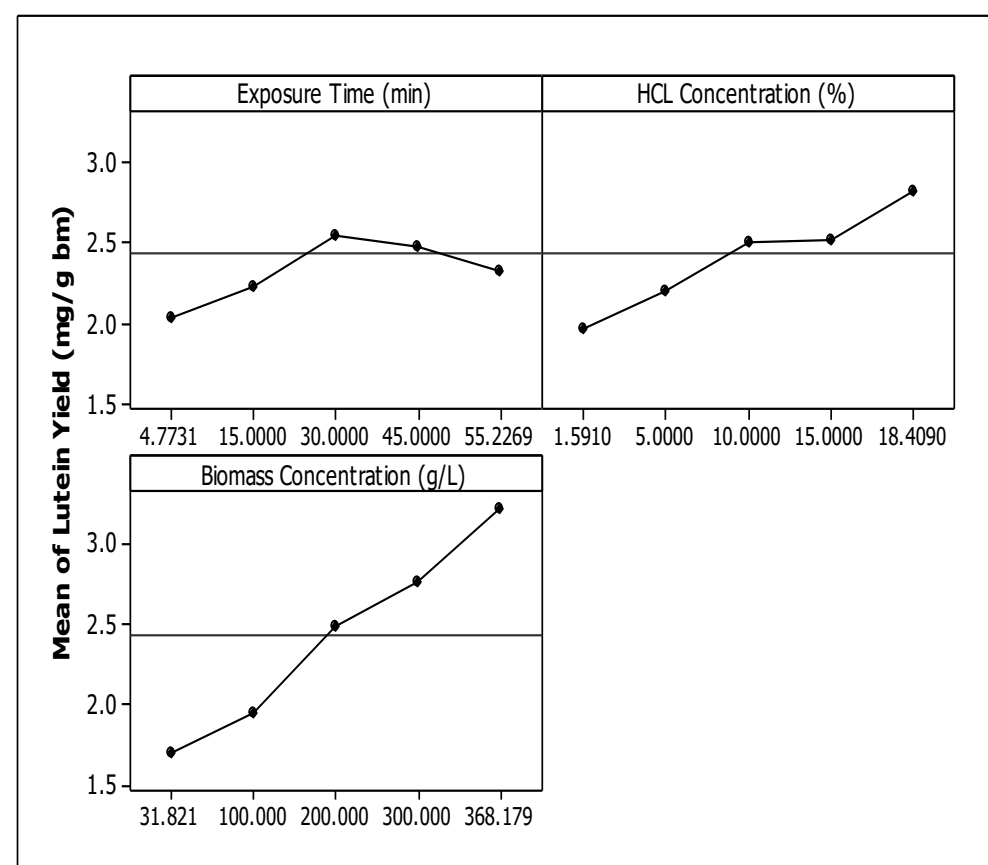

Figure 7. Main effect plot for incubation time, biomass concentration, and $\mathrm{HCl} \%$ 
The reducing power was found to be higher in $500 \mu \mathrm{g}$ concentration of $C$. pyrenoidosa $(0.783 \mathrm{mg} / \mathrm{g}$ ascorbic acid equivalent). Recently, the ethanolic extract of Enhalus acoroides exerted the potential antioxidant and ferric reducing activity (Sacristan et al., 2013) which is higher or similar to our study. ABTS radical scavenging activity of microalgae lutein is presented in Fig. 7C. ABTS radical scavenging activity was found to be higher at $250 \mu \mathrm{g}$ concentration which exerted $64.53 \%$ of antioxidant activity than other concentrations. Recently, the microalgae's Pterocladiella capillacea and Osmundaria obtusiloba also exerted more or less similar radical scavenging activity (Gao et al., 2014).

\section{Conclusion}

Ultrasound assisted extraction was applied for the lutein yield from $C$. pyrenoidosa. The response surface technique was chosen to obtain the ideal conditions of ultrasound extraction with/without acid pretreatment. The ultrasound extraction with acid pretreatment brought about the most remarkable lutein yield, trailed by ultrasound and acid extraction all together. In correlation with the acid extraction, ultrasound extraction is a more proficient and fast technique to separate the lutein from C. pyrenoidosa, because of the strong disruption of the cell wall under ultrasonic acoustic cavitation. Likewise, they had a promising anti-oxidant action which shows that this microalga can be additionally taken up for these free radical rummaging exercises. Along these lines, it is recommended that ultrasound extraction with acid pretreatment is the effective technique for the extraction of lutein.

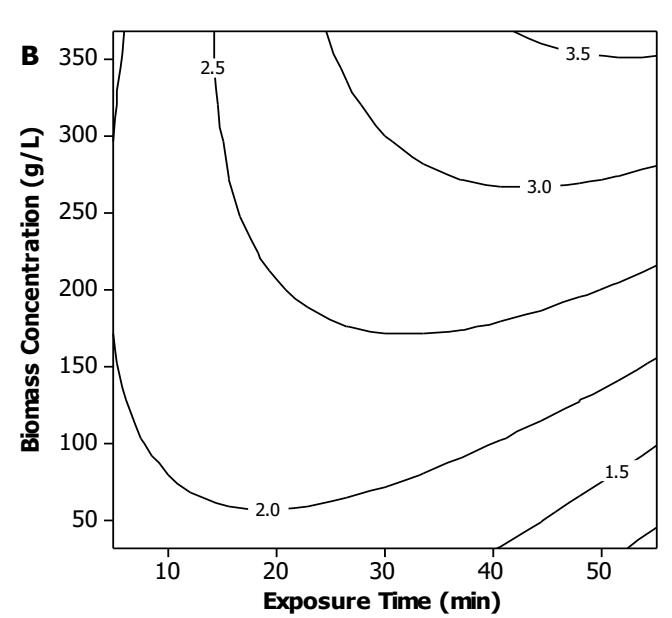

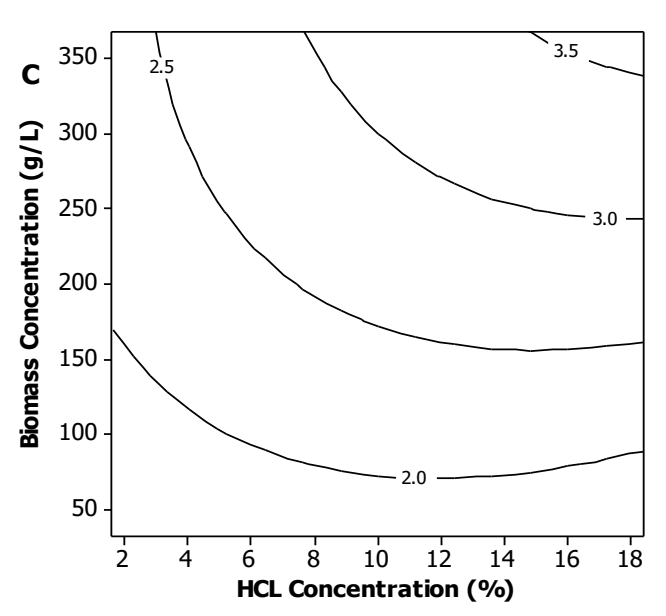

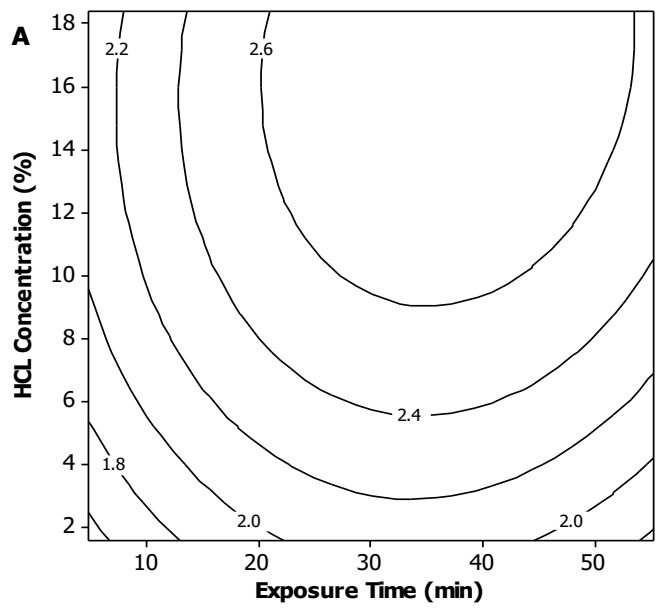

Figure 8. Multiple response surface optimisation plots for the yield of lutein from $C$. pyrenoidosa by ultrasound extraction as a function of (A) HCL concentration and incubation time, (B) biomass concentration and incubation time, and (C) biomass concentration and $\mathrm{HCL}$ concentration. 

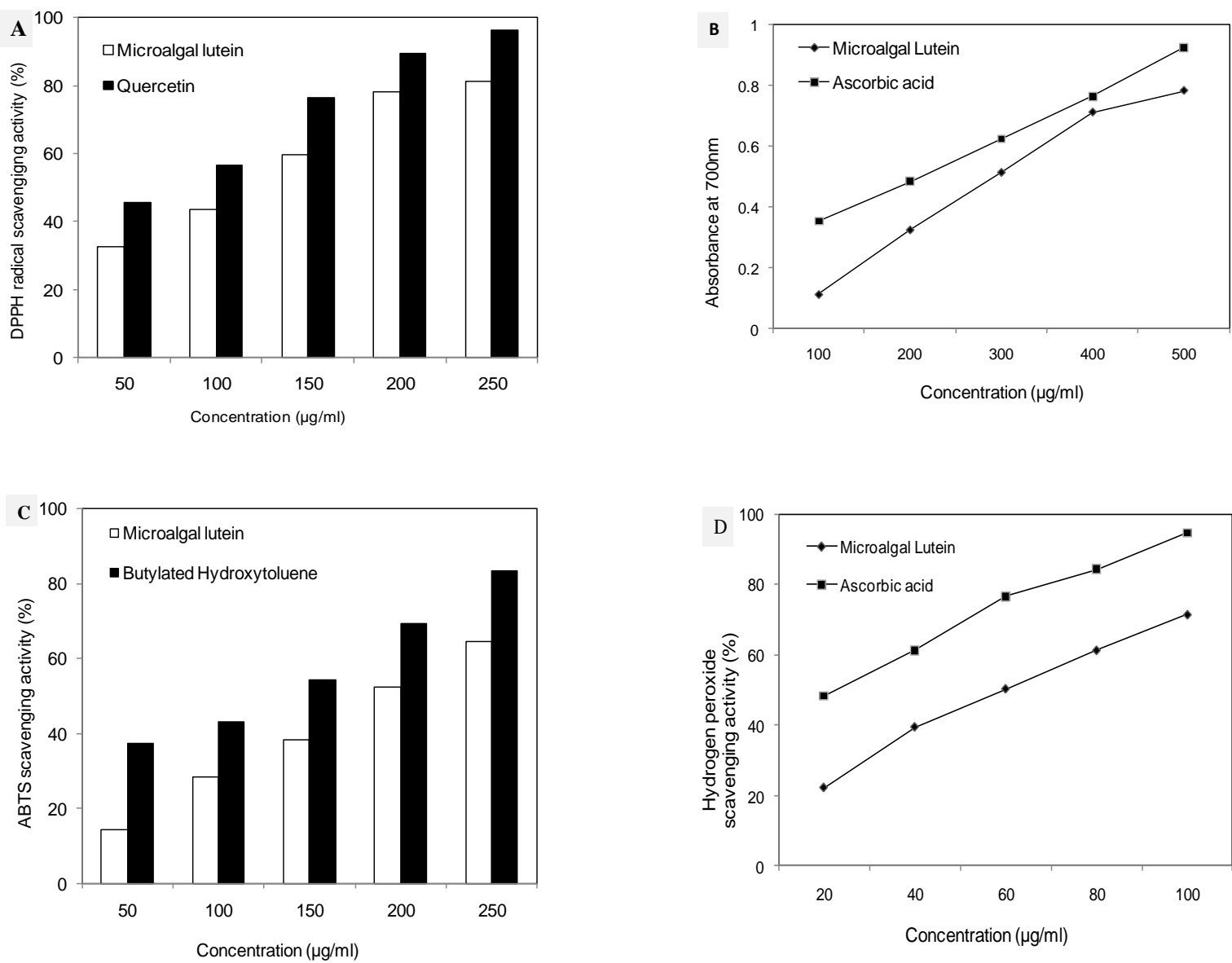

Figure 9. Antioxidant activities of microalgal lutein at different concentrations by ultrasound extraction: (A), DPPH; (B), Reducing power; (C), ABTS; (D), Hydrogen peroxide assay

\section{Acknowledgement}

The authors wish to acknowledge the SSN trust for financially supporting this study.

\section{Conflict of interest}

Authors declare we have no conflict of interest

\section{References}

Beuckels A., Smolders E. and Muylaert K. (2015), Nitrogen availability influences phosphorus removal in microalgaebased wastewater treatment, Water Res, 77, 98-106.

Blika P.S., Stamatelatou K., Kornaros M. and Lyberatos G. (2009), Anaerobic digestion of olive mill wastewater, Global NEST Journal, 11, 364-372.

Bogiatzidis C. and Komilis D. (2016), Economic and life cycle analysis of municipal solid waste management for small islands: on-site management scenarios versus off-site transportation, Global NEST Journal, 18, 197-213.

Borowitzka M.A. (2013), High value products from microalgaetheir development and commercialization, Journal of applied phycology, 25, 743-756.

Cha K.H., Lee H.J., Koo S.Y., Song D.G., Lee D.U. and Pan C.H. (2010), Optimization of pressurized liquid extraction of carotenoids and chlorophylls from Chlorella vulgaris, J. Agric. Food Chem., 58, 793-797.
Choi H.J. and Lee S.M. (2015), Effect of the N/P ratio on biomass productivity and nutrient removal from municipal wastewater, Bioprocess Biosyst. Eng., 38, 761-766.

Chou H.J., Kuo J.T. and Lin E.S. (2009), Comparative antioxidant properties of water extracts from different parts of beef steak plant (Perilla frutescens), J. Food Drug Anal., 17, 489-496.

Chua S.C., Tan C.P., Mirhosseini H., Lai O.M., Long K. and Baharin B.S. (2009), Optimization of ultrasound extraction condition of phospholipids from palm-pressed fiber, J. Food Eng., 92, 403-409.

Deenu A., Naruenartwongsakul S. and Kim S.M. (2013), Optimization and Economic Evaluation of Ultrasound Extraction of Lutein from Chlorella vulgaris, Biotechnology and Bioprocess Engineering, 18, 1151-1162.

Devi M.P., Subhash G.V. and Mohan S.V. (2012), Heterotrophic cultivation of mixed microalgae for lipid accumulation and wastewater treatment during sequential growth and starvation phases: Effect of nutrient supplementation, Renew. Energy, 43, 276-283.

Diamantis V. and Aivasidis A. (2010), Kinetic analysis and simulation of UASB anaerobic treatment of a synthetic fruit wastewater, Global NEST Journal, 12, 175-180.

Duan X., Zhang W., Li X. and Wang B. (2006), Evaluation of antioxidant property of extract and fractions obtained from a red alga, Polysiphonia urceolata, Food Chem., 95, 37-43. 
Duh P.D. (1998), Antioxidant activity of burdock (Arctiumlappa Linne): Its scavenging effect on free radical and active oxygen, JAOCS, 75, 455-465.

Fernandez J.M., Fernandez F.G.A. and Grima E.M. (2010), Biotechnological production of lutein and its applications, Appl. Microbiol. Biotechnol, 86, 27-40.

Gao F., Yang Z.H., Li C., Wang Y.J., Jin W.H. and Deng Y.B. (2014) Concentrated microalgae cultivation in treated sewage by membrane photo bioreactor operated in batch flow mode, Bioresour. Technol., 167, 441-446.

Hach. (2008). Procedure manual. Hach: Loveland CO.

Huck C.W., Popp M., Scherz H. and Bonn G.K. (2000), Development and evaluation of a new method for the determination of the carotenoid content in selected vegetables by HPLC and HPLC-MS-MS, J. Chromatogr. Sci., 38, 441-449.

Landrum J.T. (2010) Carotenoids: Physical, Chemical, and Biological Functions and Properties, CRC Press, Boca Raton, $F L, U S A$

Li T., Qu X.Y., Zhang Q.A. and Wang Z.Z. (2012), Ultrasound assisted extraction and profile characteristics of seed oil from Isatis indigotica Fort., Ind. Crop. Prod., 35, 98-104.

Macías M.D., Mantell C., Rodríguez M., Martí de la Ossa E., Lubián L.M. and Montero O. (2008), Comparison of supercritical fluid and ultrasound-assisted extraction of carotenoids and chlorophyll a from Dunaliella salina, Talanta, 77, 948-952

Muller V. (2001), An overview of the ultrasonically assisted extraction of bioactive principles from herbs, Ultrason. Sonochem., 8, 303-313.

Nagai T. and Yukimoto T. (2003), Preparation functional properties of beverages made from sea algae, Food Chem., 81, 327-332.

Ometto F., Quiroga G., Senicka P., Whitton R., Jefferson B. and Villa R. (2014), Impacts of microalgae pre-treatments for improved anaerobic digestion: thermal treatment, thermal hydrolysis, ultrasound and enzymatic hydrolysis, Water Res, 65, 350-361.

Plaza M., Santoyo S., Jaime L., Avalo B., Cifnentes A., Reglero G., Reina G., Senoráns FJ. and Ibánez E. (2012), Comprehensive characterization of the functional activities of pressurized liquid and ultrasound-assisted extracts from Chlorella vulgaris, LWT - Food Sci. Technol., 46, 245-253.

Re R., Pellegrini N., Proteggente A., Pannala A., Yang M. and Evans C. (1999), Antioxidant activity applying an improved ABTS radical cation decolorisation assay, Free Rad. Biol. Med., 26, 1231-1237

Sacristan A.M., Luna V.M., Cadena E. and Ortiz E. (2013), Green microalgae Scenedesmus acutus grown on municipal wastewater to couple nutrient removal with lipid accumulation for biodiesel production, Bioresour. Technol., 146, 744-748.

Sevilla J.M., Fernández F.G. and Grima E.M. (2010), Biotechnological production of lutein and its application, Appl. Microbiol. Biotechnol., 86, 27-40.

Subhashini N., Nagarajan G. and Kavimani S. (2011), Antiinflammatory and in vitro antioxidant property of Trigonellafoenum graecum seeds, J. Pharmacol. Toxicol., 16, 371-380.

Vlassis T., Antonopoulou G., Stamatelatou K. and Lyberatos G. (2012), Anaerobic treatment of glycerol for methane and hydrogen production, Global NEST Journal, 14,149 -156.
Yu L., Haley S., Perret J., Harris M., Wilson J. and Qian M. (2002), Free radical scavenging properties of wheat extracts, J. Agri. Food Chem., 50, 1619-1624.

Zanfini A., Corbini G., La Rosa C. and Dreassi E. (2009), Antioxidant activity of tomato lipophilic extracts and interactions between carotenoids and $\alpha$-tocopherol in synthetic mixtures, LWT Food Sci. Technol., 43, 67-72.

Zhao S.N. and Baik O.D. (2012), Application of ultrasound as pretreatment for extraction of podophyllotoxin from rhizomes of Podophyllum peltatum, Ultrason. Sonochem., 19, 22-31. 